\title{
A STUDY ON STAKEHOLDER'S SATISFACTION OF USING EDUCATION BUSINESS MANAGEMENT INFORMATION SYSTEMS (EBMIS) TOOL IN THE UNIVERSITY OF RWANDA
}

\author{
Diane Mugeni $^{1}$, Shaik NagoorMeera ${ }^{2}$, Celestin Banamwana ${ }^{3}$ \\ ${ }^{1}$ College of Business and Economics, University of Rwanda, Po. Box 3286 Kigali, Rwanda \\ ${ }^{1}$ College of Business and Economics, University of Rwanda, Po. Box 3286 Kigali, Rwanda \\ ${ }^{2}$ College of Medicine and Health Sciences, University of Rwanda, Po. Box 3286 Kigali, Rwanda
}

Diane Mugeni ${ }^{1}$ Corresponding Author

mugenidiane10@yahoo.com +250785756079

Keywords: Information Technology (IT), students, staffs, service delivery, operation

\begin{abstract}
A study aimed to investigate the role of the Education Business Management Information Systems (EBMIS) tool plays in the operation and management of the University of Rwanda focusing on staff and students. We carried out a mixed-method study in five colleges of the University of Rwanda including headquarters targeting students and staff. On the one hand, the study finds out that through EBMIS, timely application and registration online were good services whereby $25.7 \%$ of students and $27 \%$ of staff were satisfied with the services respectively. The $10.7 \%$ of students highlighted that Information technology is able to check the history of the payment process of tuition fees and $8.8 \%$ were able to access the passing modules. In addition, $55.8 \%$ of students failed to use the system during registration and application during
\end{abstract}


holidays. Consequently, students come to the registration offices for assistance by staff in each college, which is costing, and time-consuming. On the other hand, the majority of staff met the difficulties of using the EBMIS to render services in between as well as to the students due to the low skills on the system. Therefore, the students' big lines in front of offices such as offices of Colleges' registrar and repeatable claims from students are still unavoidable. Hence, the use of EBMIS is not common practice in the whole services of the colleges in University of Rwanda. About, the knowledge gap, $56 \%$ of staff do not know Information Technology System and hence $77 \%$ have not been trained at all on Information Technology System, among the trained staff, $55.1 \%$ used at least $20 \%$ of EBMIS.

The findings of the study showed that the Information Technology System is under exploitation at the University of Rwanda. However, the management of all data information from merged colleges is still critical due to the lack of technical skills and knowledge among users. Although, the University of Rwanda supports students and staff to explore this system through pieces of training in-country and abroad. Yet, there is still a big gap in skills of efficiency using the EBMIS and therefore, its productivity is still sub-standard.

\section{Introduction}

The management of Information System (MIS) is an important tool to boost organizational functions (Abishov et al., 2014). The Management Information Systems (MIS) are indispensable tools to manage data for all program processes, from the operation, supervision to evaluation and redesign. MIS is not merely repositories for data, but rather can be powerful instruments to facilitate evidence-based decision-making and to ensure program oversight and accountability. All of which contribute to better program results (Rampersad et al., 2012). 
Furthermore, the efficiency of any high academic Institutional management can be improved by providing the necessary social and economic effect $t$ (Echeverría et al., 2012). This is possible, only bypassing the transition from local subsystems of Institutional management to an integrated automatic Information System. Therefore, any information system that could cover the various aspects of the educational process, automate administrative and business activities and financial management, could provide information support to decision-making in all facets of the education Institution (Abishov et al., 2014). However, having said this, there is now a phase where the implementation needs to be consolidated at the user level, while efforts are required to implement the MIS functionalities of the system. To this effect, investments are required to develop the EBMIS support structure and tools and to develop the management reporting and general management facilities offered by the system. The EBMIS implementation can be broken down by five issues including leadership issues, organization environment issues, management process issues, personal issues, and technical systems issues.

The EBMIS (ITS product software) is a fully integrated tertiary educational management package or in other lines of business also called an ERP package. Organization-wide ERP implementations anywhere in the world typically take approximately two years. With only one year available to NUR, the progress made has been significant and satisfactory (UR, 2016)

The public higher learning institutions were five until 2012. These are the former Institutes of Kigali Health Institute (KHI), Kigali Institute of Sciences and Technology (KIST), Kigali Institute of Education (KIE), School of Finance and Business (SFB), Institute of Agriculture and Husbandry (IAH) and former National University of Rwanda (NUR). Since, 2013, all five Institutes have been merged into new one big University of Rwanda. This situation might also 
accommodate the change towards the use of existing technologies commonly used in each Institution. It is in this framework of the technology problem-solving approach, the University of Rwanda started to adopt the ITS from former National University of Rwanda (UR, 2016)

There is little information on use of EBMIS after merging the Higher Learning Institutes in one University. Even, the available literature available is limited on the system functionalities, adaptation and diffusion of the Integrated Computer Management Information System (ICMS) in different services of the University of Rwanda (Byungura et al., 2014). The same researcher highlighted the further research gaps in E-learning systems and satisfaction of EBMIS output services among end-users. Hence, further research is needed to evaluate the satisfaction levels of EBMIS in the University of Rwanda focusing on the technology problem-solving model. Therefore, the students and staff are still using classical management systems, which are not updated and not producing desired services. In addition, there is a discrepancy and duplication of information in different colleges of UR and hence, the staffs and students are not yet being able to use efficiently this ITS tool. University of Rwanda (UR) needs a strong type of information systems serving various organizational levels (Abishov et al., 2014). Since 2014, the students have applied and registered online through EBMIS. In addition, the system continued to support the new Institution by generating more information either to students or to the University staff. In the beginning, $90 \%$ of continuing students have registered themselves while $60 \%$ of newcomers have also successively registered themselves by the remained unregistered. However, the following 2015 and 2016 academic years, the number of students who applied and registered online through EBMIS has reduced dramatically due to diverse difficulties with the system (UR, 2016). This is the fact justifying the gap in the implementation of ITS product software. Hence, 
gaps are still observable such as issues in procurements process, student's marks loss and mismatch, finance issues, and management of staff (Byungura et al., 2014).

Unfortunately, if university' employees and managers believe information services are free, their demands will be infinite (Teppitaksak, 2012). One of the challenges facing institutions is to understand which systems are truly necessary, truly productive with high returns on investment and leadership integration (Rampersad et al., 2012). For such a point, UR lacks the experts for creating its own MIS database and even buys it outside; there are not qualified employees to maintain it for long-term operation. Therefore, a deep study was the most needed to find out such current gaps observed in UR and come up with the best solutions for good management of this big Institution.

\section{Methods and Materials}

The study was conducted at the University of Rwanda in five colleges and headquarters, targeted students registered from 2014 to 2016, and staff having experience of one year at the start of the study. Data were collected in four months via students and staff of the University of Rwanda concerning the current use of EBMIS. Qualitative data were generated through interviews of Deans, Directors, and Coordinators at the University of Rwanda. The total population of students were 31,760 registered in UR in 2016 distributed by Colleges with 2,327 Staffs of University of Rwanda and the $20 \%$ was considered as it is necessary to take 1 to $20 \%$ of the total population if not exceeding 1 million (WHO, 2000)'. Therefore, Study population will be 1588 students and 116 staffs.

Though, based on Yemen formula, we calculated a total sample of 319 students and 116 staff by using stratified random sampling to each college and $99.5 \%$ of the target population participated in the study. A self-administered questionnaire to the staff and students was in the English version and randomly distributed to students and Staff in each College. We also used secondary data from reports made by the former National University of Rwanda on the use of EBMIS. The quantitative and qualitative data were analyzed by descriptive statistical and thematic content 
analysis respectively. In addition, quantitative data were displayed in the graphs on different services, knowledge and practices provided through EBMIS versus the level of satisfaction among students and staff of the University of Rwanda. Both quantitative and qualitative information were mixed to make evidence.

\section{Results}

The data were collected in five colleges of the University of Rwanda and University headquarters and 319 students and 100 staff participated in our study.

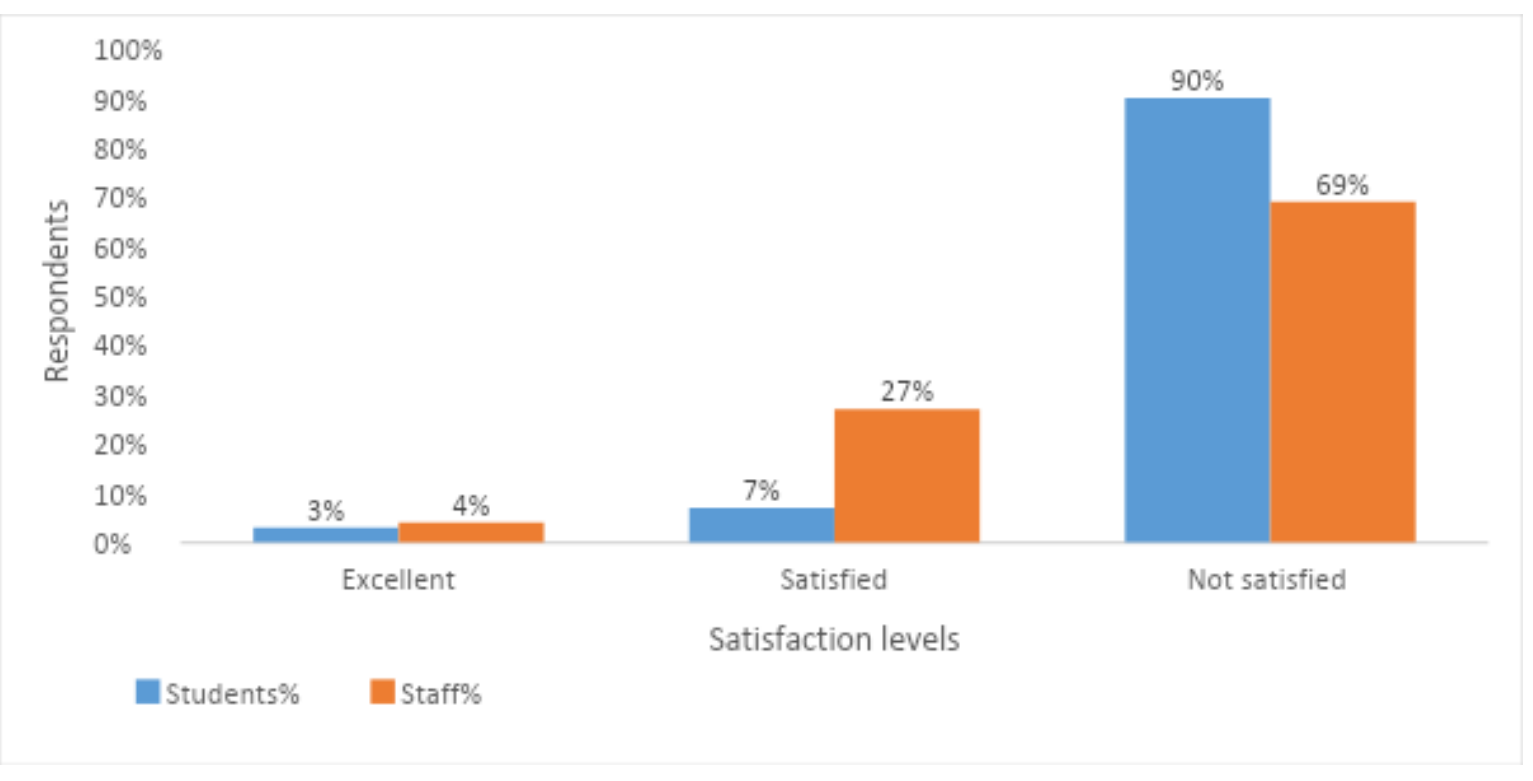

Figure 3. 1. Students and staffs satisfaction on the use of EBMIS $(\mathrm{N}=319)$

Figure 3.1.Shows that the stakeholders (Students and staff) of the University of Rwanda are not satisfied with services delivered by EBMIS at $90 \%$ and $69 \%$ respectively. This is an indicator of 
lack of implementation strategies aimed to boost the effective technology use at the entire University.

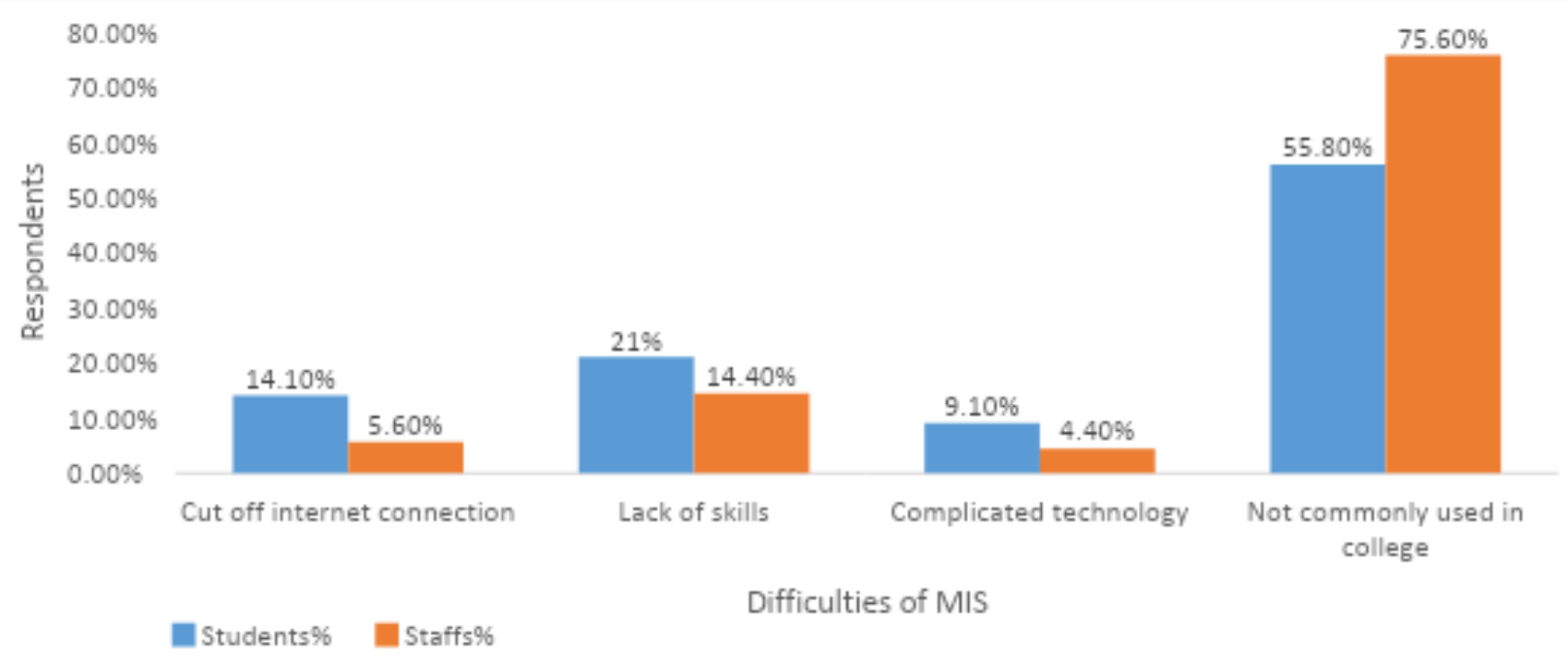

Figure 3. 2. Students and staffs' difficulties in use of EBMIS

Figure 3.2. Indicate the difficulties in the use of EBMIS. The effectiveness of MIS is humped by poor knowledge from user to the nonusers as highlighted by both students and staffs' respondents, main difficulties of MIS is not commonly used in College with 55\% and 76\% respectively. In addition, lack of skills complicates technology as indicated by students $21 \%$ and staffs $14.4 \%$. 


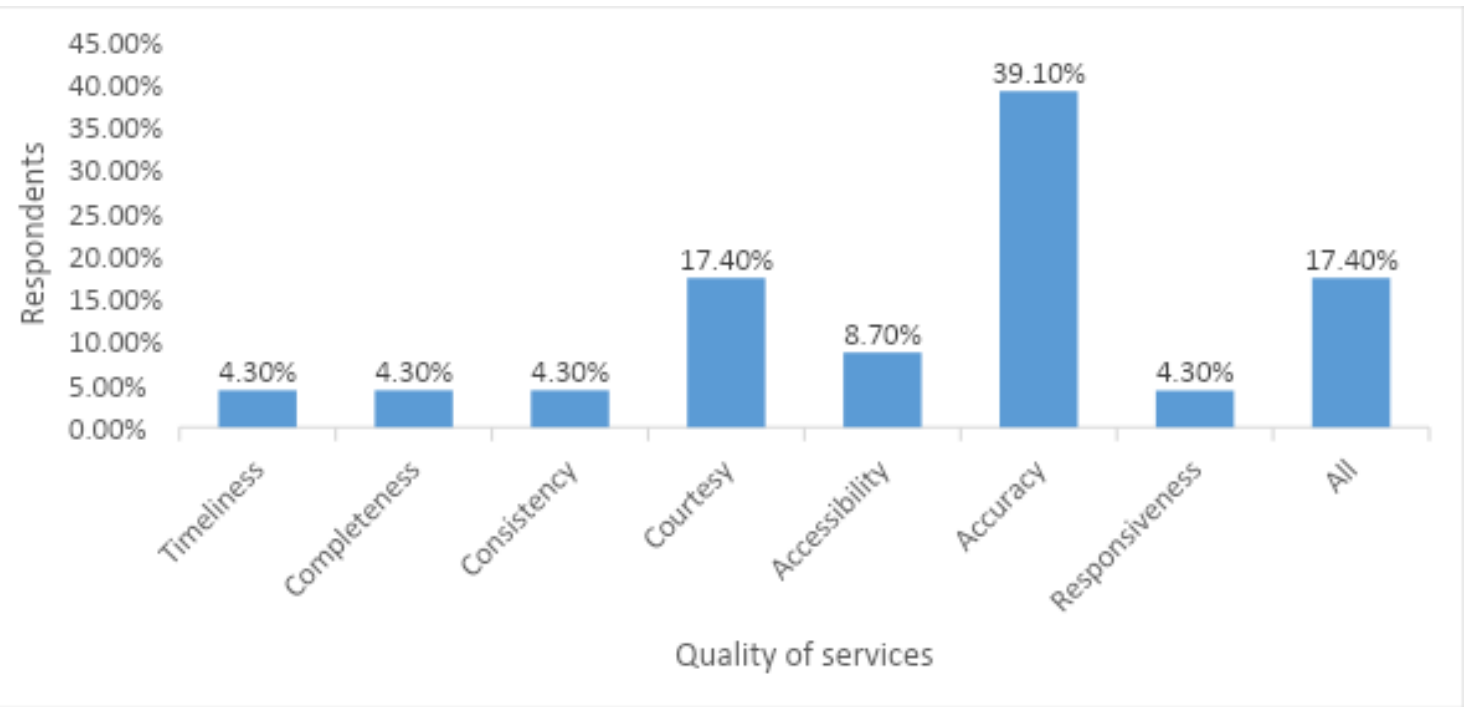

Figure 3. 3.Quality of services delivered by staff through MIS

The staff respondents of $39.1 \%$ indicated that the services provided by MIS are accurate and efficient, and $17.4 \%$ highlighted that MIS provides quality dimensions of timeliness, completeness, consistency, courtesy, accessibility, accuracy and responsiveness. The linkage of services from different unities at UR used to be done through handheld papers and documents and sometimes networking via internet and intranet connections.

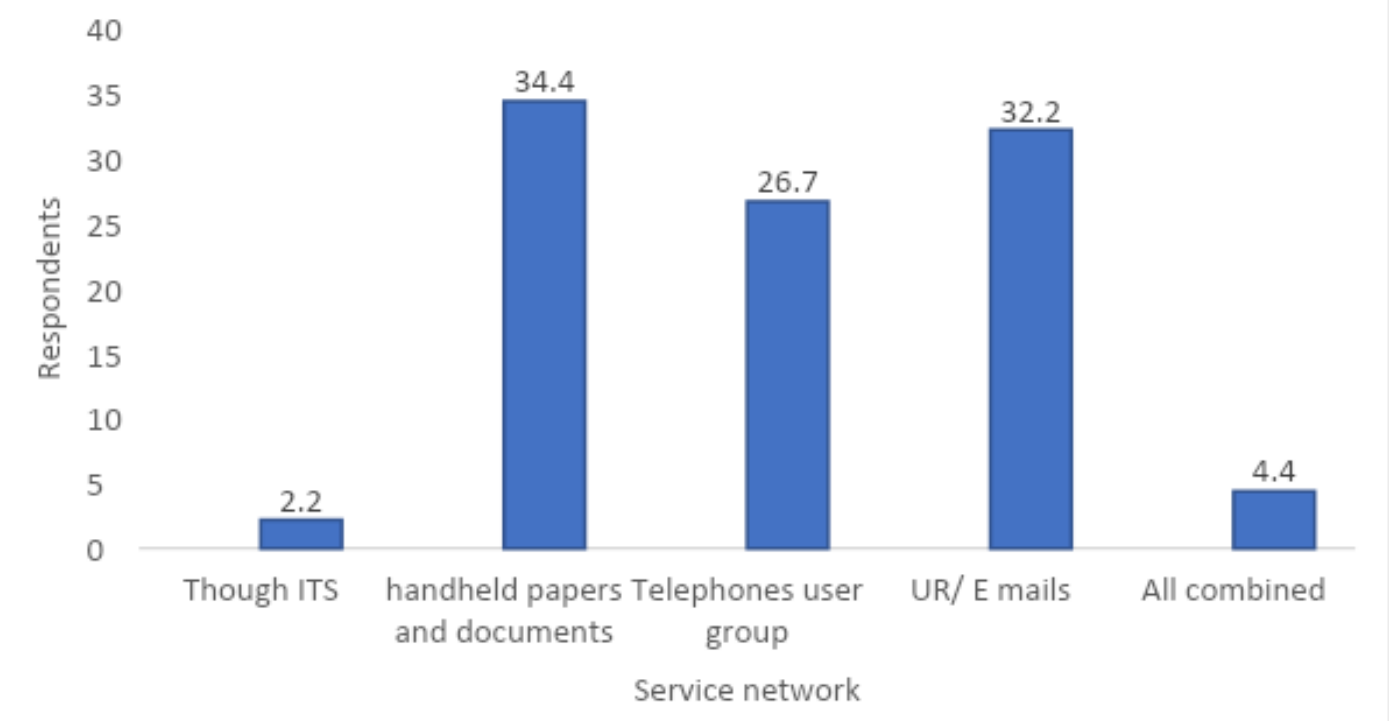

Figure 3. 4. Networking of differents Services of University of Rwanda

The staff respondent s of $34.4 \%$ 
have insisted that the only way of keeping information and get of access is basically done by handheld papers which is a classical model of keeping information. For the modern of keeping information and share, the use of internet connection serves more. However, it is not all data where this system is adopted. The use of MIS and its efficiency in UR is still critical due to knowledge gaps of staffs towards this technology as indicated in Graph 3.4

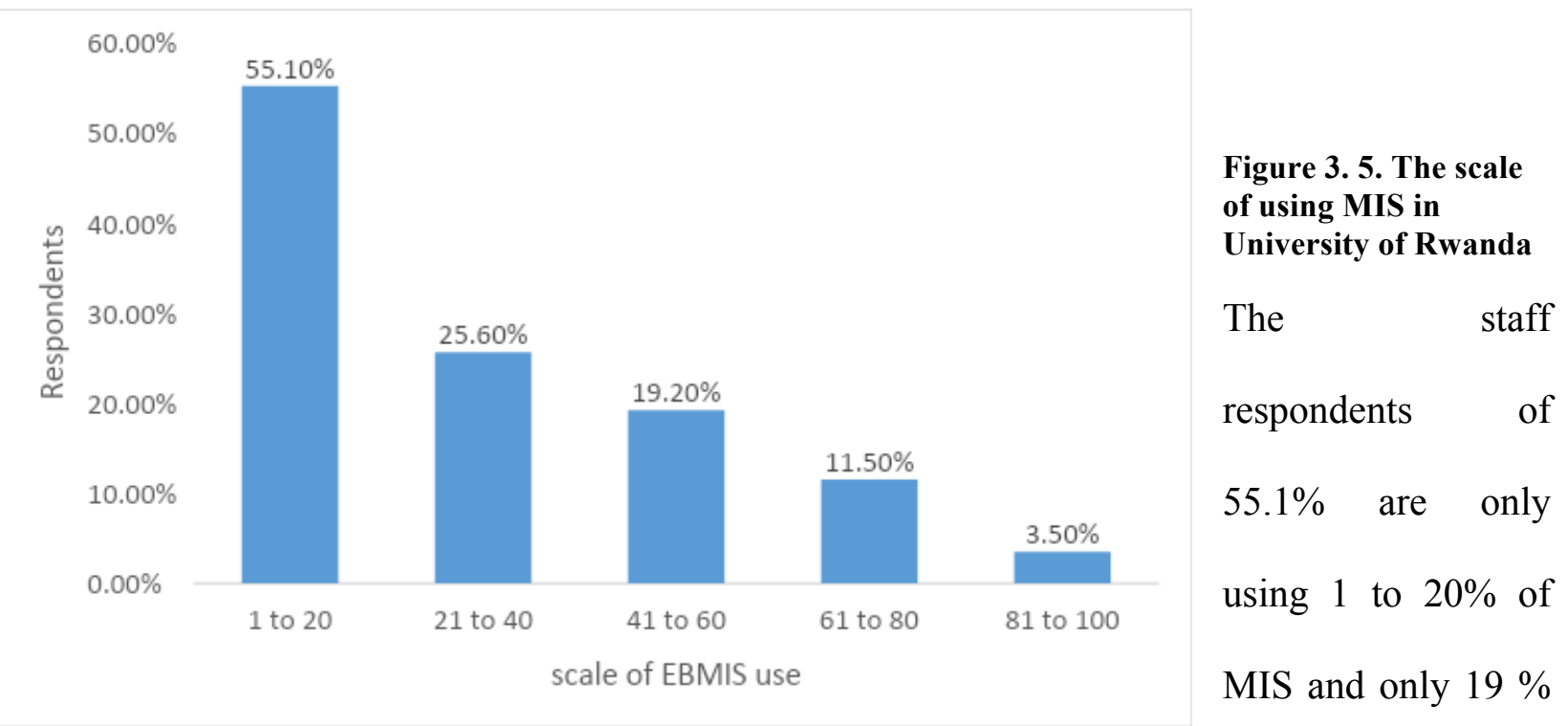

are using between 41 to $60 \%$. This is means that there is a big gap to assist the staffs to use this new technology at the University of Rwanda.

\section{Discussion}

\subsection{Meeting the needs of students and staffs through MIS}

Any information system could place at the central level the needs of stakeholder users as a paramount. The High Learning Institution could focus on the learning outcomes and teaching inputs to be successful in meeting stakeholders' needs. The EBMIS is not yet able to support all academic services provided by UR. The findings on low satisfaction of services delivered 
through EBMIS among UR stakeholders indicate that the use of EBMIS is not efficient. Such study findings are in the same angle of the study done in Turku University of Applied Sciences on lack of strategic plan and implementation of the MIS system which implied the slow adoption of the system (Kettunen, 2011). Although EBMIS was able to transform existing gaps in both learning and Teaching into the valuable quality of Education as highlighted by staff managers, the systematic evaluation of its use, by staff and others, will be better equipped to generate relevant, accurate and consistent data. Some information is credible from MIS whereby the academic information of the students such as remedial, retake are recorded with suitable payment based on the weight of Module credits and both student and staff are accessing and agree to the information as highlighted by Financial Directors of Colleges.

\subsection{Staffs aspirations and views towards MIS}

Based on interviews gathered from directors at different unities of UR, all of them agree that the MIS is a powerful tool that can assist management with all data integration and provision of good services. On interviewee, Administrator said, "It is a useful tool of keeping data together and from our point of view, it would be great if people could get all their data in and also be able to interpret the information". The same interviewee continues to highlight that for example without MIS integration, information on staff would have to be maintained separately or some missing, which would be a huge burden to the entire University. However, all new staff members who are added into the Human Resource database will have appropriate information (name, academic school, date of recruitment, experience, etc.) automatically imported into the system. The updated information for existing staff is automatically imported into the system.

The staff managers have described MIS application as useful in three primary ways, namely, by improving communication skills, education and reporting. The approach in Communication 
benefits emerges that the application improves accessibility and consistency of communication whereby everyone in University uses the same words and language (Nowduri, 2011). The fact of sharing information and online documents were also highly scored while the EBMIS option is speeding up the quality of services and time that staff or a students could use running after a document as highlighted by an interviewee.

The educational benefits of the application have the main point that raises up by interviewees whereby some of them indicated that current education is central to the technology and innovations: "It is the biggest benefit to have such EBMIS in the University of Rwanda which will serve better for future development and competence among other Universities'”. However, other interviewees have risen up a little concern that the software takes away the personal faceto-face interaction. As long as it is seen as a tool to support the personal interaction, if every information is electronically displayed, face to face interaction would be lost which are sometimes needed to handle some cases within University.

\subsection{Service delivery}

The efficient use of MIS in University is an asset to deliver good and credible information to students and staffs wherever they are in or outside Campuses (Satyanarayana Reddy et al., 2009) Some claims are still frequently presented especially during application and registration on the line of students due to fail to use themselves the MIS. Therefore, they come forward to the registration office to be assisted. Also, information regarding annual leave, retirement, and other information to the staff are still inaccessible through MIS to many staffs.

MIS serves as an interconnected set of tools, methods, and personnel used for the collection of data, storage, processing and delivery of information to the required task (Karim, 2011). The 
output fit for required decision-making. The MIS could help to analyze problems, to predict and to find optimal solutions as early as possible. Moreover, on behalf of UR staff, MIS will have embedded a complex of automation activities, information technology realizes discharge of its functions. By combining it into one system and then there is an automated information system. A man-machine system that implements automated collection and processing of information necessary for management decision-making object (Byungura et al., 2014).. However, there is a gap in expectation of MIS and current services delivered, E-learning requires an internet system, and when there is trouble shouting on the UR internet server, the system is also shortage as mentioned by a staff coordinator of E-learning in CE.

\subsection{Decision making}

Management information is data converted into information that managers can rely on at all levels in all functions to make effective and timely decisions for planning, directing, and controlling the activities for which they are responsible (Keen, 1981). However, this concern is hindered by a lack of enabling systems that can keep data and display the necessary information. Where such systems are available are not efficiently used for designed purposes particularly in developing countries. Such EBMIS introduced in the University of Rwanda has succeeded in Countries such as South Africa. However, in Rwanda, its operation is on the immature stage and tends to fail to be used in University contact due to lack of technical and administrative support.

There is a mismatch of information taken from different colleges and some information is not obtained on time and others are missed to some staff. After the reform of UR from 2013, all staff could give up existing Emails and starting the use of University Email. Although, this could be possible when all staff list integrated in MIS and display such Emails. However, up to now, staff do not have the same work Email, some are still using former Institutional Emails. 
Some decisions from academic regulations towards students are still implemented differently in UR due to the use of different systems at the level of Colleges during Marks entry, keeping, and analysis. However, different decisions are still implemented differently at University levels such as examination time table, Academic Calendar, Students memories guidelines, pass, and remedial marks. Though, the use and adaptation of MIS could provide the same quality of effective data to rely on in decision making.

\section{Conclusion and recommendations}

A study done on EBMIS in the University of Rwanda propose a framework of using this technology, which can assist both students and staff in their stakes. To improve and enabling education-based information Technology, environmental information management efforts and guidelines are necessary to put in place. Therefore, the continuous training of students and staff on the use of MIS could be urgently on the agenda of University managers.

The ICT staff could go abroad particularly on the origin of the EBMIS software to acquire knowledge and skills that can also transfer on behalf of other staff in UR. Lesson learned from users of MIS to the nonusers could be done through UR management. Especial lessons provided by human resources, ICT and student affairs, Finance Unities and academic entities of Huye Campus could be transferred to other UR campuses. Any Decision making could take the basis of data generated and provided through MIS unless they are not concerning students or and staff. The EBMIS transforms a University-wide environmental information data warehouse and more researches are needed in its evaluation and performances in the different reforms of University undergoes. Increase adoption and adaptation of MIS by replacing systematically the existing management information in different services of the University of Rwanda. 


\subsection{Conclusion}

The EBMIS is a strong system that is high costing and able to integrate all data information of big education such as the University of Rwanda. However, issues of knowledge and adoption among students and staffs' stakeholders in different Colleges and Campuses hampers its replication at the whole University. In contrast, in Huye Campus, this system is used and still presenting some technical problems such as interruption of internet, trouble shootings that require the assistance of MIS software managers or in charge of MIS at UR headquarters. Most students are not aware and family of MIS, and it is better to introduce to the newcomers towards the system during orientation week. The slowdown of using this MIS system has come after emerging of different Higher Institutions in the one University of Rwanda. Consequently, if nothing is done in the University of Rwanda to upscale using EBMIS, there is a tendency and risk of failure of using the software and fall into the financial loss which is a critical issue to the perspective of management and performance of UR.

\subsection{Recommendation}

A study done on EBMIS in the University of Rwanda propose a framework of using this technology, which can assist both students and staff in their stakes. However, the implementation gap of the model makes the system more complicated to the end users. Therefore, the enabling education-based information Technology, environmental information management efforts and guidelines are necessary to put in place. Hence, the continuous training of students and staff on the use of MIS could be urgently on the agenda of University managers. 
The University of Rwanda staffs need to share skills with the experienced EBMIS Universities where the system has been successful used for longtime by either sending the staffs abroad to learn or inviting the experts to train the EBMIS at the University of Rwanda. Any decision making could be based on data generated and provided through MIS unless they are not concerning students or and staff. The EBMIS transforms a University-wide environmental information data warehouse, more researches are needed in its evaluation, and performances in the different reforms of University undergoes. There is a need of increase of adoption of the EBMIS among stakeholders of UR by replacing systematically the existing management information systems in different services of the University of Rwanda.

\section{Acknowledgment}

We thank the University of Rwanda and Master of Business Administration coordination to allow conducting the study.

\section{Conflict of interest}

All authors declare no competing interest. 


\section{References}

Abishov, N., Asan, D., Prof, A., Kanat, A., Prof, A. \&Erkisheva, Z. 2014.Development of an Automated Information System University Management. , 143: 550-554.

Byungura, J.C, Hansson, H., \&Ruhinda, B. (2019). Integrated computer-based management information systems: The complexity and diffusion in Rwandan higher education institutions. International Journal of Education and Development Using Information and Communication Technology, 15 (1), 55-75.

Echeverría, M.A.M., Santana-Mancilla, P.C. \& Cazares, V.M.D. la R. 2012.An Educational Management Information System to Support Institutional Planning at the University of Colima.Procedia - Social and Behavioral Sciences, 55: 1168-1174.

http://dx.doi.org/10.1016/j.sbspro.2012.09.611.

Karim, A.J. 2011.The Significance of Management Information Systems for Enhancing Strategic and Tactical Planning.JISTEM Journal of Information Systems and Technology Management, 8(2): 459-470.

Keen, P.G.W. 1981.Social Impacts of Computing Information Systems and Organizational Change.Communications of the ACM, 24(1): 24--33. https://pdfs.semanticscholar.org/41c0/5e6c2cd210bb67b64adbebfb3f16fec33e58.pdf.

Kettunen, J. 2011. Management Information System in Higher Education.Encyclopedia of Information Communication Technology, (August). 
Nowduri, S. 2011. Management information systems and business decision making: review, analysis, and recommendations. Journal of Management and Marketing Research: 1-8.

Rampersad, G., Plewa, C. \&Troshani, I. 2012.Investigating the use of information technology in managing innovation: A case study from a university technology transfer office.Journal of Engineering and Technology Management - JET-M, 29(1): 3-21.

http://dx.doi.org/10.1016/j.jengtecman.2011.09.002.

Satyanarayana Reddy, G., Srinivasu, R., Rikkula, S.R. \&Sreenivasa Rao, V. 2009.Management information system to help managers for providing decision making in an organization.International Journal of Reviews in Computing: 1-6. www.ijric.org\%0Awww.ijric.org/volumes/Vol5/1Vol5.pdf.

Teppitaksak, P. 2012. Management information systems development for the Office of the President Nakhon Phanom University.Research in Higher Education Journal: 1-10.

UR. 2016. Statistics Office. : 31. 